
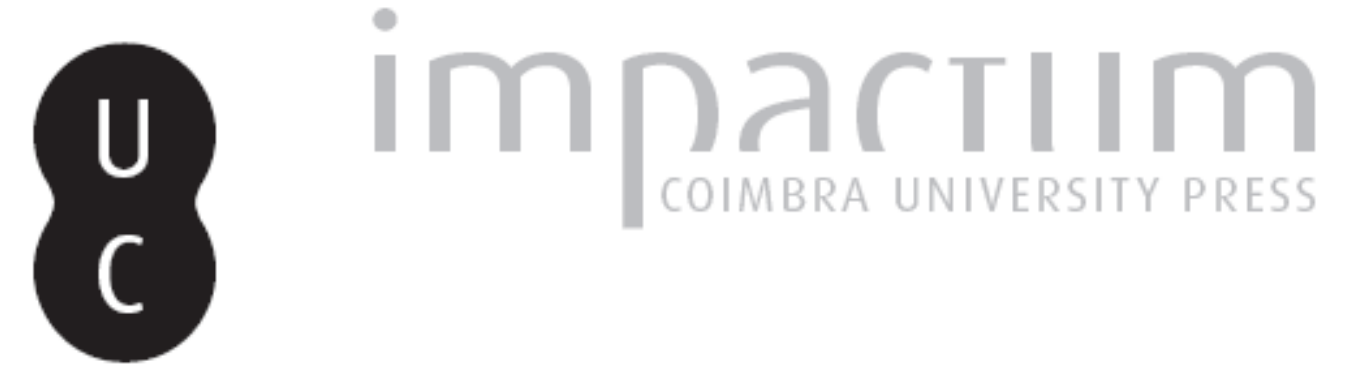

\title{
[Recensão a] Fontana F., La villa romana di Barcola, a proposito delle villae maritimae della Regio X
}

Autor(es): Lancha, Janine

Publicado por: Imprensa da Universidade de Coimbra

URL persistente:

URI:http://hdl.handle.net/10316.2/45467

DOI:

DOI:https://dx.doi.org/10.14195/1647-8657_34_9

Accessed : $\quad$ 26-Apr-2023 10:46:07

A navegação consulta e descarregamento dos títulos inseridos nas Bibliotecas Digitais UC Digitalis, UC Pombalina e UC Impactum, pressupõem a aceitação plena e sem reservas dos Termos e Condições de Uso destas Bibliotecas Digitais, disponíveis em https://digitalis.uc.pt/pt-pt/termos.

Conforme exposto nos referidos Termos e Condições de Uso, o descarregamento de títulos de acesso restrito requer uma licença válida de autorização devendo o utilizador aceder ao(s) documento(s) a partir de um endereço de IP da instituição detentora da supramencionada licença.

Ao utilizador é apenas permitido o descarregamento para uso pessoal, pelo que o emprego do(s) título(s) descarregado(s) para outro fim, designadamente comercial, carece de autorização do respetivo autor ou editor da obra.

Na medida em que todas as obras da UC Digitalis se encontram protegidas pelo Código do Direito de Autor e Direitos Conexos e demais legislação aplicável, toda a cópia, parcial ou total, deste documento, nos casos em que é legalmente admitida, deverá conter ou fazer-se acompanhar por este aviso.

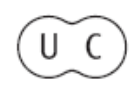


UNIVERSIDADE DE COIMBRA

FACULDADE DE LETRAS

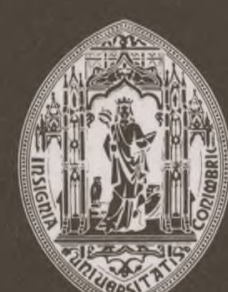

CONIMBRIGA

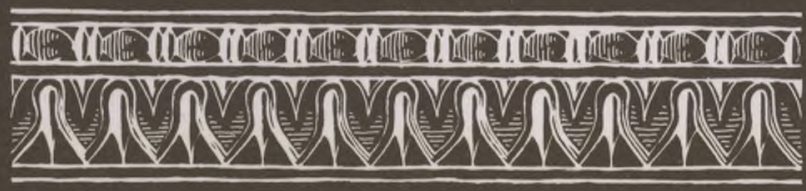

VOLUME XXXIV - 1995

INSTITUTO DE ARQUEOLOGIA 


\section{RECENSÕES BIBLIOGRÁFICAS}

FONTANA F., La villa romana di Barcola, a proposito delle villae maritimae della Regio X, Rome, 1994.

Cette monographie consacrée à une villa suburbaine et "maritime" des environs immédiats de Trieste (Istrie) constitue le 4ème volume des Studi e ricerche sulla Gallia cisalpina, collection dirigée par G. Bandelli et M. Verzar Bass.

Elle s'inscrit dans un programme de recherches de l'Université de Trieste et affronte un sujet difficile: de la villa, fouillée en 1887, rien n'est visible sur le terrain et le matériel recueilli - mosaïques, monnaies, céramique, marques sur briques - n'est accessible qu'en partie au Museo civico de Trieste.

Les trois rapports de fouilles et les plans dus à l'inventeur, A. Puschi, constituent la base de la réflexion de l'A., qui donne ainsi un bon exemple de ce que peut être une "fouille d'archives" éclairée par l'esprit critique de l'archéologue et de l'historienne qu'est F. Fontana.

L'ouvrage analyse successivement l'histoire de la découverte (pp. 15-25) le plan de la villa (p. 16-78) le matériel archéologique (pp. 79-146) les trois phases de construction (pp. 157-167) la côte triestine (pp. 171-196) et trace un tableau de comparaisons avec les villas maritimes en Italie (pp. 201-211). Une conclusion (pp. 217-230), et une bibliographie (pp. 231-270) complètent l'ouvrage, qui comprend en outre 65 figures et un plan hors texte.

L'A. démontre d'abord la cohérence de l'ensemble que les éditeurs précédents considéraient comme deux villas séparées, la villa della statua et la villa à palestre et nymphée. La villa de Barcola est une luxueuse villa maritime dont la première implantation peut être attribuée au deuxième quart du 1er s. av. J.C., la deuxième phase à l'époque augustéenne et la troisième au deuxième quart du 1er s. ap. J.-C. (cf. fig. 39, 40 et 41). Elle appuie son analyse chronologique sur l'étude des mosaïques, qu'elle situe dans leur contexte architectural et qui ont l'avantage d'être visibles, pour la plupart, au Museo civico de Trieste, comme le donne à voir la couverture de l'ouvrage. Après les études, anciennes, de M. E. Blake et celles, récentes, de M. Donderer (Die Chronologie der römischen Mosaiken in Venetien und Istrien bis zur zeit der Antonine, Berlin, 1986) à ce sujet, peut-être eût-il fallu publier ces mosaïques d'une manière différente? les dessins 
au trait d'A. Puschi ont le mérite de donner la composition d'ensemble de ces 54 pavements, dont 31 ont un décor géométrique, mais ils ne donnent aucun détail et les rares photographies des mosaïques dans l'ouvrage de F. Fontana sont des vues de détail.

On se demande pourquoi les nombreux fragments exposés au Musée n'ont pu être photographiés de manière satisfaisante afin de permettre la réalisation de montages photographiques - un puzzle facile à réaliser, dans ce cas On est d'autant plus surpris que, dans l'ouvrage de M. Donderer cité supra, de bonnes photographies sont publiées.

Dans ces conditions, le lecteur ne peut se faire une idée de la partie conservée par rapport à la partie visible à la découverte et, surtout, il ne peut apprécier la beauté du style - sévère - ni les effets optiques recherchés dans ce type de composition et bien analysés par l'A. dans le texte.

$\mathrm{Du}$ point de vue méthodologique, on regrette que les descriptions ne reprennent pas la terminologie acceptée internationalement dans ce domaine celle du Décor géométrique, par C. Balmelle et alii, Paris, 1985. Elles se limitent aussi au tableau central et ignorent le reste du tapis. On aimerait aussi savoir, systématiquement, si l'analyse et la date proposées concordent avec celles de M. Donderer, ou si une divergence n'existe que dans un cas, le $\mathrm{n}^{\circ} 51, \mathrm{p} .124$, où elle est justifiée par l'A.

Par ailleurs, il fallait naturellement publier les plans d'A. Puschi. Mais une mise au net de ces plans, réunis, avec une indication plus visible des numéros et des lettres de situation des pièces aiderait le lecteur à suivre plus facilement les descriptions de l'A.

Ces remarques n'ôtent rien à la qualité de l'ouvrage qui tient esssentiellement dans la relecture, attentive et critique, d'un ensemble exceptionnel daté de la fin de la République à 50 ap. J.-C.

L'A. consacre une partie importante de son étude au contexte historique, économique et social de cette villa maritime, comparable aux plus beaux exemples découverts dans le Latium et en Campanie. En particulier, les pages consacrées aux propriétaires virtuels de la villa, P. Clodius Quirinalis, préfet de la flotte de Ravenne à la fin du règne de Claude, puis Calvia Crispinilla, "magistra libidinum" de Néron sont tout à fait éclairantes sur l'importance de ces édifices à la fin de la République et au I er s. de l'Empire.

On voit donc que l'étude de $\mathrm{F}$. Fontana est très informée, très suggestive, mais qu'elle aurait peut-être gagné, en ce qui concerne les mosaïques, à être présentée d'une manière plus raisonnée, dans la description, et plus sensible, dans l'illustration, à la qualité technique de ces documents. L'A. ne pose pas non plus le problème de l'exécution de ces mosaïques par un atelier précis (venu d'Aquilée ou de Rome?).

JANINE LANCHA

Conimbriga, 34 (1995), p. 205-222 